\title{
EL PAPEL DEL ESTADO EN LA CONFIGURACIÓN DE LA REALIDAD ACTUAL DE LAS SOCIEDADES PESQUERAS EN MÉXICO
}

\section{The state's role in shaping the present reality of fishing companies in Mexico}

\section{AURA HELENA RAMÍREZ CORONA · FRANCISCO JAVIER VERDUZCO MIRAMÓN*}

Fecha de recepción: 1 de diciembre de 2015- Fecha de aprobación: 29 de marzo de 2016

\section{Resumen}

Este trabajo ofrece un panorama general sobre las sociedades pesqueras que históricamente se han desarrollado en el territorio mexicano, y enfatiza en el papel desempeñado por el Estado en la configuración de las mismas a partir de la década de 1940, vinculándolo con los retos y desafíos que dichas sociedades enfrentan hoy día.

Palabras clave: sociedades pesqueras; México; Estado; Costa del Pacífico; Desarrollo.

\section{Abstract}

This paper presents a general perspective on the fishing societies that have developed historically in Mexico, emphasizing the role played by the State in their configuration since the 1940s and linking this to the challenges these societies confront today.

Keywords: fishing societies; Mexico; the State; Pacific coast; Development.

* Doctorantes del Programa de Doctorado en Ciencias Sociales con Especialidad en Estudios Rurales del Centro de Estudios Rurales (CER) de El Colegio de Michoacán, A.C., México. Correo-e: auramurux@yahoo.com.ar 


\section{Introducción ${ }^{1}$}

El presente artículo pretende examinar los procesos de desarrollo, en los que las sociedades pesqueras mexicanas se han visto involucradas -a partir de la década de 1940- en el marco de la intervención estatal, con el fin de dar cuenta de los retos y desafíos que estas enfrentan actualmente, para continuar con su modo de vida.

Si bien es cierto que la pesca en México tiene una larga historia, cuyos registros se remontan a la época prehispánica, ante la complejidad de la problemática por la que pasan actualmente los grupos humanos que habitan y hacen uso de los diversos recursos de los ecosistemas acuático terrestres de este país, nos parece que atender al periodo en el que -de acuerdo a Graciela Alcalá- la intervención del Estado sobre las actividades pesqueras comenzó a hacerse sistemática, resulta una imperiosa necesidad.

En este empeño, el texto comienza por hacer un detallado recuento sobre la manera en la que el Estado ha intervenido estas actividades, en pos del desarrollo económico del sector y de las regiones costeras del territorio mexicano, a través de la política pública, centrada en las acciones y objetivos de los diversos proyectos emprendidos con el fin de modernizar la costa, al igual que sus actividades productivas.

Posteriormente se discute el concepto de desarrollo, y se ofrece un panorama general de los conflictos que actualmente aquejan a las sociedades pesqueras. Mediante el que se intenta explicitar algunas de las contradicciones generadas -en los espacios en los que estas se desenvuelven- a causa de la implementación de numerosas iniciativas que, en nombre del crecimiento económico, han pasado por alto que estos lugares están en su mayoría habitados.
Y, por último, se muestran - a través de los casos de los ejidos costeros de Campos en Colima y el Rebalsito de Apazulco en Jalisco- las formas en las que los retos y desafíos que enfrentan dichas poblaciones se relacionan, tanto con el ejercicio de la planeación estatal de las actividades pesqueras y el territorio costero, como con la manera en la que esta se ha transformado.

En este sentido, el trabajo de campo realizado en ambos lugares entre los años 2009 y 2015, se basó en la observación participante, y tuvo como herramienta principal la entrevista a profundidad de corte narrativo, así como el registro minucioso de numerosas conversaciones informales. Las indagaciones en el terreno estuvieron enfocadas a seguir el desenvolvimiento de los proyectos de desarrollo implementados en lo local. Es decir, a intentar dar cuenta de sus objetivos y de los intereses inmiscuidos en ellos; al igual que de los efectos generados y las respuestas surgidas entre los habitantes de ambos lugares.

En tanto que la investigación bibliográfica se centró en la revisión de algunos textos en los que se discute la transformación de la noción de desarrollo; así como en el análisis de los casos a los que -desde la antropología- refieren las diferentes investigaciones relacionadas a las sociedades pesqueras aquí citadas.

De esta manera, trataremos de vislumbrar -en el apartado correspondiente a las conclusiones- cómo es que la intervención del Estado mexicano sobre las actividades y espacios de los que depende la pesca ribereña se encuentra vinculada, con los retos y desafíos que encaran sus sociedades hoy día. 
I. La intervención estatal en la configuración de las sociedades pesqueras, un breve recorrido (1946-2015)

Dentro de lo que actualmente conocemos como el territorio mexicano existen numerosos espacios acuático-terrestres de gran importancia social, económica y medioambiental. Los ríos y arroyos que recorren el país constituyen una red hidrográfica que se extiende por 633 mil kilómetros de longitud; los lagos y lagunas más importantes refrescan las tierras de catorce entidades federativas; y los manglares recorren los 11,122 kilómetros de litoral que se bañan en las aguas del Océano Pacífico, del Mar Caribe y los golfos de México y California (SEMARNAT, 2013). De manera que no es de extrañar que la presencia de diversos grupos humanos en estos espacios se remonte a tiempos inmemoriales y que los podamos encontrar a lo largo de todos los periodos históricos de nuestro país.

En este sentido, diversos autores han documentado los importantes logros alcanzados por las sociedades pesqueras durante la época prehispánica, en cuanto al conocimiento y desarrollo de artes y técnicas de pesca especializadas para cada medio (Luque \& Robles, 2007; Marín, 2000; Dachay, 1985). Al igual que han señalado la relevancia económica que tuvieron la explotación de perlas en Baja California durante la conquista; la entrega en concesión de la explotación del nácar y la tortuga en el Porfiriato (Cariño \& Monteforte, 2011); y la industrialización de la pesca del atún, la sardina, la anchoveta y el abulón en Ensenada a principios del siglo XX (Ochoa, 1988).

No obstante, consideramos que para entender de mejor manera la problemática actual de estas sociedades, es necesario atender al rol que ha desempeñado el Estado en los procesos de desarrollo y modernización de estas regiones, a través de la implementación de diversas políticas públicas. Puesto que si bien estas iniciativas persiguen objetivos específicos relacionados con el crecimiento económico de las actividades que impulsan, también han sido, por lo general, apropiadas por las poblaciones receptoras conforme a sus propios intereses.

\section{I.1 La intervención estatal y el desarrollo costero}

Desde la fundación de la Organización de las Naciones Unidas (ONU) y de los primeros grupos financieros internacionales de la posguerra, como el Banco Mundial (BM) y el Fondo Monetario Internacional (FMI) en 1945, pero sobre todo ante el anuncio del presidente norteamericano Harry S. Truman -al final de la década de 1940de que la entonces mayor potencia productiva extendería los beneficios del progreso hacia los países que se encontraran en la búsqueda del crecimiento económico (Esteva, 2000), el Estado mexicano se ha caracterizado por institucionalizar la mayor parte de las políticas promovidas en este sentido por aquellas.

Así, durante el mandato presidencial de Miguel Alemán Valdés (1946-1952), se fomentó la construcción de carreteras al igual que la electrificación de ciudades y zonas rurales, con el fin de incrementar la producción agrícola e industrial (Delgado \& Cantú, 2008). Esta situación tuvo -aunque indirectamente- un impacto positivo en el sector pesquero, puesto que contribuyó al uso de sistemas de enfriamiento para conservar las especies capturadas, así como a facilitar su traslado en grandes cantidades para su comercialización (Alcalá, 2003). 
Sin embargo, también creó la Secretaría de Recursos Hidráulicos y en su interior la sección de Fomento a la Pesca y posteriormente, en 1950, estableció la Dirección General de Pesca Industrial y Conexas, cuyo objetivo fue la planificación de la actividad (Op.cit.: 42). A la infraestructura eléctrica y carretera su sumó la draga y modernización de los puertos con mayor importancia en el país: Manzanillo, Colima; Lázaro Cárdenas, Michoacán y Salina Cruz, Oaxaca en el Océano Pacífico; al igual que Altamira, Tamaulipas y Veracruz, Veracruz en el Golfo de México.

Más tarde, Adolfo Ruiz Cortines (1952-1958) impulsó a nivel nacional el programa de "La Marcha al Mar" y el "Progreso Marítimo". El primero de ellos fomentó la migración hacia las costas del Pacífico mexicano, que demandaban tanto gente que la poblara como mano de obra para las labores portuarias. Mientras, el segundo, dotó de infraestructura a los puertos dada la importancia comercial de las zonas litorales del Pacífico y el Golfo de México (Ídem.: 45-46).

Como resultado de ello, nuevas poblaciones fueron fundadas en las regiones costeras del Pacífico mexicano. Tal es el caso de los rancheros que descendieron de la Sierra Madre del Sur hacia las costas michoacanas y jaliscienses tras haber sido beneficiadas por el reparto agrario, en donde aprendieron las artes de la pesca y la navegación (López, 2001).

Una década después -durante la administración de Adolfo López Mateos (1958- 1964)-, el crecimiento de la población en general y la migración que este desató hacia la Ciudad de México y otros centros urbanos, derivaron en la necesidad de proveer estos espacios con alimentos a precios bajos (Alcalá, 2003).
Entonces se pensó que a través del fomento de las actividades pesqueras y de la regulación del precio de las especies capturadas, se podría contribuir a satisfacer una parte de las necesidades alimenticias de la población. Con base en ello se creó la Secretaría de Industria y Comercio, encargada de regular el valor de las especies en el mercado nacional. Además se estableció el Instituto Nacional de Pesca, orientado hacia la investigación, evaluación y manejo de los recursos pesqueros; al igual que la Comisión Consultiva de Pesca, que formuló el primer Programa Nacional de Fomento (Op.cit.: 47).

No obstante, durante el sexenio de Gustavo Díaz Ordaz (1964-1970), el fomento a la actividad se limitó a la pesca de camarón y a la habilitación de los puertos pesqueros de Yucalpetén en Yucatán, y San Carlos en Sonora (Ídem: 48). Por lo que su sucesor, Luis Echeverría Álvarez (1970-1976), hubo de solicitar ante la ONU² la asistencia económica internacional, con el fin de hacer de la pesca una de las principales actividades productoras de alimentos. La respuesta fue positiva, y a partir de los créditos otorgados se crearon un gran número de empleos que beneficiaron a los pequeños y medianos productores, que se interesaron en organizar cooperativas pesqueras. Pero también se fomentó la creación de las mismas inclusive en donde no había pescadores de oficio.

En este sentido, la implementación del Programa Nacional de Desarrollo Pesquero conocido como "Las Mil Lanchas", facilitó la adquisición de embarcaciones y artes de pesca de manera rápida y eficiente. Además el gobierno declaró como zona económica exclusiva las 200 millas contiguas a las costas, con lo que los pescadores mexicanos fueron los únicos con 
el derecho de capturar las especies de mayor importancia comercial en este espacio. Junto con ello, en 1971 creó la paraestatal Productos Pesqueros Mexicanos (ProPeMex), para encargarse de gestionar los registros de las cooperativas; brindar los créditos necesarios para la adquisición de embarcaciones, motores y artes de pesca; instalar procesadoras de pescado, y finalmente de acopiar y comercializar los productos del mar (Marín, 2003). Lo que en su conjunto modificó la dinámica de la actividad y contribuyó a su crecimiento acelerado (Op.cit.: 55).

Los resultados concretos del impulso pesquero se observaron durante el sexenio presidencial de José López Portillo (19761982), toda vez que los volúmenes de captura se incrementaron hasta ocupar el decimotercer lugar mundial y, a su vez, el segundo puesto en monto de divisas obtenidas por productos como camarón, langosta y abulón. Ante tal escenario, se creó la Secretaría de Pesca como institución responsable de la planificación del sector a nivel nacional. No obstante, tras la devaluación del peso mexicano -que tuvo lugar con el cambio de gobierno- muchas de las paraestatales como ProPeMex se hallaban en quiebra, y con ella las principales pesquerías del país (Ídem: 60).

A partir de entonces, el interés gubernamental por el desarrollo de la pesca decayó. De modo que, durante el mandato de Miguel de la Madrid Hurtado (1982- 1988) el apoyo a la pesca se redujo a la construcción del complejo -de capital francés y holandés- "Pesca Industrial Corporativa, S.A.", en las costas de Colima y Chiapas (Ídem: 68).

En tanto que en el periodo de Carlos Salinas de Gortari (1988-1994), lejos de impulsar la producción nacional, se fomentó la competencia por las especies antes exclusivas de las cooperativas y se cerró el Banco Nacional Pesquero. Lo que en su conjunto provocó el declive -y en algunos casos la quiebra- de muchas pesquerías, sobre todo en el sector industrial, como en el caso de las cooperativas camaroneras (Ídem: 71).

Sobre esta misma línea, el mandato de Ernesto Zedillo Ponce de León (1994-2000) se caracterizó por el cierre de la Secretaría de Pesca y la creación de la Secretaría del Medio Ambiente, Recursos Naturales y Pesca (SEMARNAP). La medida política no tuvo una justificación clara, sobre todo cuando la pesca había sido reconocida nacional e internacionalmente, como una importante actividad económica con dinámicas propias, obstáculos singulares por superar y con actores sociales definidos e identificados. Con ello la importancia de la pesca disminuyó ante la problemática del cuidado de las especies acuáticas y el deterioro del medio ambiente (Ídem: 79).

El declive de la actividad pesquera tomó fuerza durante el mandato presidencial de Vicente Fox Quesada (2000-2006), cuando este sector fue borrado por completo de las acciones prioritarias que se proyectaron en el Plan de Desarrollo Nacional. De esta manera la pesca dejó de ser una parte importante de la política nacional, y la intervención gubernamental priorizó la conservación de los recursos naturales y el desarrollo del turismo, por encima de las necesidades de las sociedades pesqueras.

De igual forma, aunque en los sexenios de Felipe Calderón Hinojosa (2006-2012) y de Enrique Peña Nieto (2012-2018), algunas actividades pesqueras -como la acuicultura- volvieron a cobrar importancia dentro del Plan Nacional de Desarrollo, esto no significó que el resto de las actividades pesqueras fueran contem- 
pladas en ello, ni que el acceso a los espacios de los que estas dependen fuera garantizado a las poblaciones locales. Por lo que los conflictos que desde la década de 1970 comenzaron a gestarse, a causa de la implementación de diversos proyectos para la modernización del campo, han seguido apareciendo.

\section{Los conflictos en las sociedades pesque- ras ante la intervención estatal}

Como se puede ver, en los espacios en los que se han formado y desarrollado las sociedades pesqueras de nuestro país confluyen numerosos actores con intereses diversos, los que si bien han generado algunas fuentes de empleo para la población local, también han propiciado numerosos conflictos por el control del territorio y sus recursos.

El sector empresarial nacional e internacional interesado en invertir en cierto tipo de actividades productivas, al igual que el Estado, en tanto que interviene para determinar qué actividades se priorizan y a quiénes se les da cabida en la implementación de los proyectos de desarrollo, constituyen quizás los actores más importantes con los que aquellas tienen relación. Pues en conjunto han conseguido implementar diversas iniciativas sobre los territorios en los que las sociedades pesqueras se desenvuelven, que han implicado -de manera cada vez más sistemática- la expulsión de las poblaciones locales de estos espacios.

Resulta innegable la importancia que, en términos económicos, han tenido los puertos de altura ubicados en las costas de Michoacán, Nayarit, Jalisco, Sinaloa, Colima, Oaxaca y Veracruz. Sin embargo, indiscutible resulta también el hecho de que transformaron por completo el medio del que dependían las actividades de los pescadores ribereños, al haber sido instalados sobre diversos cuerpos de agua utilizados para la captura de peces y mariscos. Además, en el caso de los últimos tres referidos, se ha sumado la competencia con la pesca industrial, ya que ambos cuentan con una terminal especializada en el manejo de flotas atuneras.

Por otro lado, el sector energético ha convertido el agua en la materia prima para la producción de energía eléctrica, siendo la termoeléctrica e hidroeléctrica los principales mecanismos para su generación. El común denominador alrededor de esta infraestructura han sido los conflictos con las poblaciones pesqueras, quienes argumentan que la cantidad de captura de especies ha disminuido a partir de la operación de este tipo de proyectos. El caso de la Central Termoeléctrica "Manuel Álvarez Moreno" en la Laguna de Cuyutlán, Colima; al igual que los de las hidroeléctricas de "El Infiernillo" sobre el cauce del río Balsas en Michoacán; y las de Malpaso, La Angostura, Chicoasén y Peñitas sobre el río Grijalba en Chiapas, dan cuenta de este tipo de conflictos.

Asimismo, la actividad minera y la generación de energía eólica han provocado numerosas afectaciones a los ecosistemas en torno a los que se desarrollan las sociedades pesqueras. En el estado de Guerrero, por ejemplo, doscientos cincuenta pescadores de la comunidad de Nuevo Balsas esperan ser indemnizados por la minera Media Luna, a causa de los daños provocados al ambiente durante los trabajos de exploración; en tanto que en la costa huave en Oaxaca, los campos eólicos han modificado los vientos y las corrientes marinas alterando por completo el hábitat natural de las especies que históricamente han aprovechado. 
Finalmente, en este breve recorrido por algunos de los conflictos que atraviesan las sociedades pesqueras mexicanas hoy día, no podrían faltar los provocados por la expansión de la industria turística e inmobiliaria, pues este sector es el que mayores altercados ha generado entre las poblaciones pesqueras, a causa de la competencia que se establece por la ocupación de un mismo espacio y el aprovechamiento de sus recursos.

Los escenarios en los que dicho tipo de disputas se han presentado, se extienden a lo largo de una buena parte de los litorales, ríos y aguas interiores mexicanas. Sin embargo, la situación se hace más evidente en las costas de los estados de Campeche, Quintana Roo (Riviera Maya), Jalisco (Costa Alegre) y Nayarit (Riviera de Nayarit) donde cadenas con renombre internacional han construido lujosos complejos hoteleros.

Ante el panorama anteriormente esbozado, llama la atención el hecho de que, en la búsqueda de la ruta hacia el desarrollo, el Estado mexicano haya intervenido sobre los territorios de los que dependen las sociedades pesqueras mexicanas, para priorizar actividades económicas como la portuaria, la minera, la energética o la turística. Beneficiando con ello tanto al sector empresarial nacional y extranjero, como a algunos miembros de la clase política mexicana que -a través de estas medidas de planificación territorial- se han ido apropiando de los espacios y recursos necesarios para la supervivencia de aquellas.

En este sentido, la afirmación de Norman Long sobre el hecho de que, sin importar que la idea del desarrollo se haya originado en la obsesión de la llustración por el progreso y la modernidad; o el que esta haya adquirido impulso a partir de que Harry S. Truman la hiciera el emblema de su campaña colonizadora, la significación que esta palabra adquiere actualmente varía de acuerdo al contexto y a la persona que la emplea (Long, 2007).

A continuación, veremos de qué manera es que se expresa esta situación en dos contextos particulares, así como las formas en las que ambas poblaciones han participado de los procesos de desarrollo costero.

\section{Retos y desafíos en la pesca ribereña: dos casos de estudio en el Pacífico mexicano}

En este último apartado intentaremos mostrar los retos y desafíos a los que se enfrentan los pescadores ante la intervención gubernamental -sobre la actividad pesquera y el territorio costero- en dos espacios del Pacífico mexicano.

\section{III.1 La pesca ribereña en la Laguna de Cuyutlán}

La fundación del poblado de Campos data de 1906, cuando ante las necesidades operativas del posible puerto que se planeaba construir al interior de la Laguna de Cuyutlán, fue preciso crear un nuevo pueblo y un campamento de trabajadores ferrocarrileros, sobre lo que hasta entonces era una estación de carga y bodegas (Mendoza, 2011). Si bien la actividad pesquera no fue el factor determinante para el nuevo asentamiento, desde entonces esta y la agricultura han sido actividades que han generado importantes ingresos económicos y alimentos para las familias.

En ese sentido, el 11 de marzo de $1931^{3}$ un grupo de habitantes del poblado solicitaron al entonces gobernador Laureano Cervan- 
tes Vázquez (1927-1931) que les dotara con terrenos para cubrir sus necesidades económicas. Un año después, el 11 de junio de 1932, la Comisión Local Agraria autorizó la dotación de un total de 959 hectáreas de tierra, expropiadas a Ferrocarriles Nacionales de México, a "Hacienda de Cuyutlán" y a la "Hacienda de El Colomo", en una proporción de 152, 443 y 384 hectáreas respectivamente.

Sin embargo, diez años después algunos vecinos del poblado volvieron a solicitar tierras al Gobernador del Estado en turno ${ }^{4}$, Pedro Torres Ortiz, para trabajarla y satisfacer sus carencias económicas. Luego de un proceso de desacuerdos y defensa por la posesión del suelo entre los afectados y beneficiados, el Departamento Agrario emitió el fallo a favor de los solicitantes. Así, el 30 de diciembre de 1944 se otorgó la ampliación por 1,344 hectáreas al ejido de Campos, Manzanillo, expropiadas a la "Hacienda de El Colomo" ${ }^{5}$.

De esta forma el ejido de Campos quedó constituido por un total de 2, 303 hectáreas divididas en dos fragmentos, el primero ubicado sobre una franja costera entre el Océano Pacífico y la Laguna de Cuyutlán; y el otro al norte del mismo cuerpo de agua, colindante con los ejidos de Miguel de la Madrid, El Colomo y la Arena, así como con el casco urbano histórico de Manzanillo.

Por su cercanía a la Laguna de Cuyutlán, la población de Campos se ha vinculado de manera directa con la actividad pesquera -ya sea integrándose como miembros de alguna cooperativa o de forma libre- y padecido la intervención gubernamental que ha priorizado el crecimiento portuario e industrial en el municipio de Manzanillo.
La Laguna de Cuyutlán se localiza en el litoral del Océano Pacifico sobre la planicie de costa en el estado de Colima. Su forma alargada cubre una superficie cercana a las siete mil 200 hectáreas a lo largo 37 kilómetros de línea costera, con una anchura de entre cinco y seis kilómetros que se extienden sobre los municipios costeros de Manzanillo y Armería. Por su extensión, se sitúa dentro de los primeros cuatro ecosistemas lagunares a nivel nacional, mientras que a nivel estatal representa el $90 \%$ de los humedales existentes.

La laguna representa el hábitat natural de peces y crustáceos con gran valor comercial, por lo que hoy día se encuentran sobreexplotados. Del primer conjunto destacan la mojarra la lisa, el pargo la tilapia, el robalo de aleta amarilla y la corvina; mientras que el segundo lo componen principalmente el camarón, la jaiba y el langostino.

\section{III.1.2 La intervención estatal: planificación e industrialización}

Históricamente tanto el ejido de Campos como la Laguna de Cuyutlán, han sido considerados como territorio estratégico para el desarrollo de la actividad industrial y portuaria, por lo que la actividad pesquera ha quedado rezagada dentro de la política pública.

La estrategia política de planificación del territorio manzanillense quedó registrada en el Plan Director de Desarrollo Metropolitano de 1975, donde ante el inminente crecimiento portuario fue necesario disponer de espacios para atender la proyección comercial del hinterland de San Pedrito. Así, la Laguna de Cuyutlán quedó disponible como reserva, pese a que en primera instancia fue destinada para la explotación racional de recursos pesqueros. 
Como parte de dicha planificación, a finales de 1970 se construyó la Central Termoeléctrica "Manuel Álvarez Moreno" sobre suelo perteneciente al ejido de Campos y a la orilla de la laguna. La operación de esta obra resultó un duro golpe para la actividad pesquera, toda vez que para la generación de la energía eléctrica se requirió agua, por lo que fue reabierto el canal de Ventanas que conectó el Océano Pacífico con el ecosistema lagunar.

Los pescadores han manifestado su desacuerdo con la operación de la Central debido a que han observado una progresiva disminución de las especies de la laguna, lo que ha repercutido en los bajos volúmenes de captura obtenidos diariamente, y provocado que el producto de la pesca alcance solo para el autoconsumo, cuando antes representaba un ingreso seguro a los hogares (Santana, 2013).

Sin embargo, en la última década la situación para los pescadores ribereños se ha complicado, toda vez que el crecimiento industrial y portuario no se ha detenido. En el año 2008 fue construida la Planta de Tratamiento de Gas Natural Licuado, también sobre las tierras del ejido de Campos y a orilla de la Laguna de Cuyutlán. Además, como obras complementarias se realizaron la ampliación del canal de Tepalcates; el dragado de parte de la laguna para posibilitar la navegación de los barcos metaneros dentro del ecosistema; la instalación de torres de alta tensión eléctrica y la construcción de la carretera Campos-Punta Chica y el desvío ferroviario sobre el cuerpo de agua.

Aunado a todo lo anterior, el día 24 de julio de 2009 se entregó el título de concesión en favor de la "Terminal KMS de GNL, S. de R.L. de C.V." para usar bienes de dominio público de la federación, sobre una extensión de 5 mil 892.33 metros cuadrados para la construcción y operación de una terminal portuaria de altura de uso particular, que se destinará a la recepción de gas natural licuado 6 . Y dos años más tarde, el día 23 de diciembre de 2011 se decretó la habilitación del vaso II de la Laguna de Cuyutlán para navegación de altura y cabotaje del puerto.

\section{III.1.3 El cooperativismo en la Laguna de Cuyutlán}

Las sociedades cooperativas dieron a sus miembros la seguridad de mantenerse "oficialmente" en la actividad, así como la posibilidad de tener derechos sobre determinadas zonas de pesca al interior de las lagunas o en alta mar. Si bien esta estrategia gubernamental puesta en marcha durante la década de 1970 resultó positiva para algunos pescadores ribereños de la Laguna de Cuyutlán, también trajo consigo algunos conflictos que hasta la actualidad siguen vigentes.

La intervención gubernamental a partir del cooperativismo a nivel nacional, estuvo dirigida en gran medida hacia la industrialización del sector pesquero, ya que su producción resultaba más importante en función de las divisas que le atraen. Por el contrario, según el argumento oficial, la pesca ribereña era un medio de subsistencia tan solo para el grupo doméstico de los pescadores, por lo que no se consideró rentable. Desde entonces, esta situación ha derivado en la disputa constante entre estos dos sectores, el ribereño y el industrial (Alcalá, 1986).

Pese al interés de la iniciativa, en Colima fueron solo veinticinco las cooperativas constituidas. La mayor parte de ellas se dedicaron a la pesca de peces de escama, así como a la del camarón de 
laguna y de estero, mientras que tan solo cuatro orientaron sus actividades a la pesca de camarón en alta mar. De estas, más de la mitad fueron registradas en el municipio costero de Manzanillo y se centraron en la pesquería ribereña al interior de la Laguna de Cuyutlán.

La creación de las cooperativas camaroneras de aguas interiores, surgió del interés de la Secretaría de Pesca por controlar a los pescadores de subsistencia de la Laguna, a través de la regulación de sus actividades; pero también por el de intervenir sobre el acceso a un recurso que disminuía aceleradamente a causa tanto de las actividades de la termoeléctrica, como del aumento de la densidad de población en esta zona y de la constante violación a los periodos de veda del crustáceo. Lo que ha representado un duro impacto en la economía y alimentación de las familias dedicadas al aprovechamiento del camarón.

\section{III.2 Rodeados de tanta agua era nuestro destino hacernos pescadores. El caso de EI Rebalsito de Apazulco, Jalisco}

El Rebalsito de Apazulco es un poblado costero asentado sobre las tierras del ejido Lázaro Cárdenas que fue fundado en 1942, en lo que hoy constituye parte del municipio de La Huerta en el estado de Jalisco.

El núcleo poblacional que, de acuerdo al INEGI, actualmente cuenta con alrededor de seiscientos habitantes, se encuentra ubicado en medio de diversos ecosistemas acuáticoterrestres como el río Purificación; los acantilados de Las Coloradas y la Punta Dos hermanos; la marisma de La Zacatosa; el estero de
La Vena; las lagunas costeras de La Boca y Tenacatita; y finalmente, las playas de Tenacatita, Mora, Pedreguera.

Todos estos espacios históricamente han constituido una importante fuente de alimentos, materias primas y trabajo asalariado para los locales. No obstante, hoy día la continuidad de las diversas actividades que en ellos se llevaban a cabo se encuentran en entredicho, a causa del avance de la industria turística e inmobiliaria. A continuación, haremos un recorrido a vuelo de pájaro a lo largo de la historia del lugar para comprender la relevancia que estos espacios tienen para la población local, así como para vislumbrar los principales retos que enfrentan hoy día.

\section{III.2.1 "Trajimos gente por mar que nos ayudó a fundar el ejido éste"}

Hasta poco antes de la fundación de El Rebalsito de Apazulco, en la región costera del estado de Jalisco, prevalecieron las grandes propiedades que en manos de algunos jefes del ejército constitucionalista -y con base en el peonaje de familias de trabajadores- producían algunos frutos tropicales. La Hacienda de Apazulco de José Uribe era una de ellas.

Es posible que los primeros escritos de los que se tiene registro en la Secretaría de la Reforma Agraria (SRA) -que hacen constar que en 1932 un grupo de hombres solicitó tierras para fundar un ejido en este lugar- hayan sido hechos por estos trabajadores. Sin embargo, no serían ellos los que diez años después se beneficiarían con la dotación. 
Cuenta el viejo Andrés Vargas -el último de los fundadores de El Rebalsito que aún vive-, que al principio de la década de 1940 él y su padre se encontraban en Barra de Navidad, donde todos los días se embarcaban rumbo a Chamela en una canoa de parota movida por el viento, en busca del tiburón (Vargas, 2015).

En una de esas expediciones, los Vargas llevaron con ellos a un hombre que desembarcó en Tenacatita, se internó en el monte y regresó al cabo de unas horas con una hoja de papel. Miguel Arraquera -el padrino de Andrés- había descubierto un cajón de madera en la enramada de un pequeño campo de cultivo abandonado, en cuyo interior encontró -además de algunas herramientas oxidadas- un papel muy maltratado que según decía, era para pedir tierras para formar un ejido.

Los Vargas echaron a andar la solicitud, y al cabo de un año consiguieron que algunas familias radicadas en Cihuatlán se desplazaran por tierra hasta El Rebalsito, para sumarse a la empresa de fundar un ejido junto al mar. No obstante, la cantidad de personas que ahí se establecieron aún era insuficiente para justificar la dotación de tierras por lo que -una vez que la SRA notificó que se presentaría para realizar el censo- Andrés y su padre recurrieron a los habitantes de las poblaciones vecinas para completar un número de treinta hombres -en edad de trabajar y que fueran jefes de familia- que se censaran junto con ellos.

Así, las últimas veinte familias que fueron registradas -en el conteo hecho para conseguir la ejecución de la dotación de tierras- llegaron y regresaron por mar a sus respectivos hogares al cabo de poco tiempo, en las canoas de Andrés y de su padre José Vargas.
A partir de entonces, quienes se asentaron en la ribera del río Purificación comenzaron a desarrollar un sistema diversificado de producción para el autoconsumo, que combinaba la producción familiar de frutas y verduras con el aprovechamiento estacional de los recursos del río, el mar, las lagunas y el estero, a través de la pesca, la caza, y la recolección.

Algunos de los productos de la caza como las pieles del jaguar, el winduri, el venado y el caimán, así como las plumas de la garza real eran transportados en canoa hasta Barra de Navidad, Cihuatlán o Manzanillo, para poder adquirir -a través de su venta- nuevas municiones, aperos de labranza y artes de pesca. En tanto que los productos de la pesca, la agricultura y la recolección se reservaban para el consumo familiar (Ramírez, 1989).

De esta manera transcurrieron los primeros diez años de vida ejidal, hasta que -a mediados de la década de 1950- comenzaron a llegar nuevos pobladores al ejido que impulsaron la agricultura comercial, y que poco a poco acapararon la mayor parte de las tierras fértiles. Durante este periodo, que se extendió hasta los años setenta, la abundancia de recursos en el mar, el río y las lagunas permitió la supervivencia de las familias de quienes hasta 1972 -cuando se consiguió la ampliación de tierras-, se emplearon cotidianamente en el jornal agrícola para obtener un salario.

\section{III.2.2 "Yo me acuerdo que los primeros que se jueron para allá..." La aparición del turismo y la modernización pesquera}

Con la ejecución de la ampliación de tierras del ejido se obtuvieron tierras poco aptas para la agricultura, pero colindantes con el mar. De 
esta forma la población local ganó el reconocimiento de los derechos para usufructuar los recursos de unos terrenos que de facto ya aprovechaban, a través de la pesca, la caza, la recolección y la prestación de diversos servicios a los aún contados turistas que comenzaron a llegar durante los años sesenta.

Además, lo anterior posibilitó que en medio del auge cooperativista, fuera fundada, en 1974, la Sociedad Cooperativa de Producción Pesquera Ejidal Tenacatita de Rebalsito y que -poco a poco- la bahía de Tenacatita se fuera poblando con restaurantes rústicos de madera y palapa atendidos por la población local.

A lo largo de los primeros diez años de vida de la cooperativa -que coincidieron con el tiempo de operación de ProPeMex-, las actividades pesqueras en El Rebalsito se transformaron por completo, pues quienes se asociaron a la Cooperativa únicamente habían practicado la pesca con fines de autoconsumo desde la orilla del mar o en pequeños cayucos, con anzuelos, fisgas de mangle y atarrayas de fibras naturales. De esta manera, una gran diversidad de especies de escama era capturada en las aguas que rodean al ejido, al mismo tiempo que se recolectaban caracoles, diferentes especies de cangrejos y camarones, lapas, ostiones, chacales o huevos de tortuga, y se cazaba a los mapaches, tejones, venados, jabalíes, armadillos y tortugas que se acercaban a aquéllas para beber o desovar.

Muchas de estas actividades se siguieron practicando por muchos años a la par que la pesca ribereña. Sin embargo, la cooperativización de las actividades pesqueras implicó la formación de un grupo de hombres que centra- ron sus esfuerzos en unas pocas especies de importancia comercial. Asimismo, la obtención de créditos para la adquisición de embarcaciones de fibra de vidrio, motores fuera de borda e hilos de nylon permitió a los socios incrementar de manera significativa sus volúmenes de captura, lo que convirtió a la pesca en una actividad económicamente remunerada de suma importancia para la población local.

No obstante, la incorporación de las actividades pesqueras rebalsiteñas en el sistema de producción, comercialización y consumo provisto por ProPeMex incentivó la creación de sólidas relaciones de dependencia entre el grupo de pescadores y la paraestatal. Debido a ello, la relevancia económica de la cooperativa se desplomó, cuando a mediados de los años ochenta aquella fue desmantelada, para no recuperarse sino hasta diez años más tarde con la consolidación de Tenacatita como destino turístico.

\section{III.2.3 "A gusto se la pasaba uno junto al mar en Tenacatita, pero pus ni modo". El auge del turismo rústico, la revitalización de la pesca comercial y el desalojo de la playa}

La década de 1990 estuvo marcada para los locales, por el inicio del conflicto por los terrenos aledaños a Tenacatita contra el empresario José María Andrés Villalobos; pero también por la consolidación de la bahía como destino turístico.

La transformación de la brecha que comunicaba al Rebalsito con la carretera costera en tramo carretero, permitió la llegada de una cantidad cada vez mayor de turistas nacionales y extranjeros, que demandaban servicios de alimentación, hospedaje y entretenimiento. 
Fue entonces que el aprovechamiento de los recursos costeros volvió a cobrar importancia en cuanto fuente de empleo remunerado, pues durante los periodos vacacionales y días de asueto -en los que la afluencia turística se incrementaba- los pescadores abastecían los restaurantes locales, además de ofrecer sus servicios como guías y timoneles durante las temporadas de pesca deportiva, clases de buceo y recorridos en lancha por el manglar; en tanto que un gran número de mujeres y jóvenes se empleaban como cocineras, meseras y vendedoras ambulantes.

Así, desde 1995 y hasta el año 2010, la mayor parte de la población de El Rebalsito sobrevivió con base en el aprovechamiento diversificado y estacional de los recursos de su entorno a través de la prestación de servicios turísticos; de la pesca comercial y la de autoconsumo; de la recolección de moluscos, crustáceos y huevos de tortuga; y de la caza eventual de iguanas, armadillos, jabalíes y tejones. Lo que también les permitió sostener el conflicto contra el empresario José María Andrés Villalobos económicamente y mediante la ocupación del territorio-, hasta que fueron desalojados por la policía estatal al final de este periodo.

El conflicto por la concesión de la Zona Federal Marítimo Terrestre de Tenacatita sigue sin tener un resultado definitivo, pero independientemente de ello, es precisamente lo que esta disputa en particular representa -el avance de la industria inmobiliaria sobre los espacios costeros en donde numerosas poblaciones habitan y se ganan la vida día con día-, lo que constituye el principal de los desafíos que esta localidad enfrenta actualmente.

\section{Conclusiones}

A lo largo de este artículo hemos intentado mostrar, cómo es que las sociedades pesqueras que históricamente se han asentado en el territorio mexicano no solo se han dedicado a la extracción de los recursos pesqueros, sino que, por el contrario, han desplegado una serie de sistemas de conocimiento y aprovechamiento de los ecosistemas acuático-terrestres que habitan que les ha permitido construir ciclos diversificados de producción, acordes a cada medio.

Así, las sociedades pesqueras combinan actividades como la caza, la recolección, el comercio, el intercambio de diversos productos, la agricultura y la prestación de servicios turísticos con su principal modo de vida, en función de las posibilidades que existen para aprovechar los recursos pesqueros. Es por ello que consideramos necesario ampliar dicha noción, para poder contemplar la complejidad de las implicaciones de este modo de vida.

Ahora, si bien la particularidad del medio en el que se llevan a cabo las labores de la pesca da origen a una cultura propia que distingue a estas sociedades de las que no están ligadas al medio acuático-terrestre, la intervención estatal ha desempeñado un papel clave en su configuración, en la del territorio, y en la del campo de fuerzas en el que la pesca ribereña se desarrolla.

En este sentido, podemos decir que la planificación del territorio ha priorizado las actividades secundarias y terciarias -provocando numerosas disputas a causa del traslape de actividades sobre un mismo espacio-, en detrimento de las primarias, y que los insuficientes créditos otorgados por las instituciones gubernamentales para el fomento pesquero han actuado como 
mecanismos de control, que han provocado en la mayoría de los casos- profundos conflictos entre quienes se dedican a la actividad.

Por su parte, el cooperativismo dio certeza y derechos a sus miembros para desarrollar la pesca, también resultó útil como mecanismo de control gubernamental sobre las zonas y las especies posibles de capturar. A la vez, al interior del padrón de agremiados propició los conflictos entre sus integrantes y con otros por la adquisición de los recursos materiales y económicos entregados, así como la disputa por las especies pesqueras con mayor demanda en el consumo popular.

Los escenarios que hemos descrito en el presente artículo son muestras concretas de que la pesca no ha sido una actividad favorecida por el Estado, por el contrario, los pescadores han sufrido una serie de restricciones políticas y la reducción de su espacio laboral y social, de los cuales han logrado salir avante poniendo en práctica sus propios recursos para continuar con su fuente de ingresos económicos.-

sobre el Comercio y el Desarrollo celebrado en Chile, en 1972.

${ }^{3}$ Publicado en el Periódico Oficial del Estado de Colima.

${ }^{4}$ Publicado en el Periódico Oficial del Estado de Colima, con fecha del 2 de enero de 1943.

${ }^{5}$ Diario Oficial de la Federación. Resolución en el expediente de ampliación de ejidos al poblado de Campos, Estado de Colima. Publicado el día 13 de julio de 1946 (pp. 26-28).

${ }^{6}$ Publicado en el Diario Oficial de la Federación con fecha del día 24 de julio del año 2009.

\section{Referencias bibliográficas}

Alcalá, G. (2003). Políticas pesqueras en México (1946-2000). Contradicciones y aciertos en la planificación de la pesca nacional. México: El Colegio de México, Centro de Investigación Científica y de Educación Superior de Ensenada, El Colegio de Michoacán. (1999). Con el agua hasta los aparejos. Pescadores y pesquerías en el Soconusco, Chiapas. México: CIESAS, UNICAHCIAD.

(1985) Los pescadores de Tecolutla: el tiempo cotidiano y el espacio doméstico. México: SEP, CIESAS (Cuadernos de la Casa Chata, Serie Los pescadores de México).

Cariño, M. \& Monteforte, M. (2011). "Las perlas y los hombres en el Golfo de California, 1500- 2005”. En Alcalá, G. (ed.). Pescadores de América Latina y el Caribe: espacio, población, producción y política, Vol. I. México: UNAM.
Dachay, A. (1985). El Caribe mexicano: hombres e historias. México: SEP, CIESAS (Cuadernos de la Casa Chata, Serie Los pescadores de México).

Delgado de Cantú, G. (2008). Historia de México. Legado histórico y pasado reciente. México: Pearson Educación.

Esteva, G. (2000). "Desarrollo". En Viola, A. Antropología del desarrollo. Barcelona: Paidós lbérica.

Long, N. (2007). "La construcción de un marco conceptual e interpretativo". En Sociología del desarrollo: una perspectiva centrada en el actor. México: CIESAS, El Colegio de San Luis.

López Santillán, Á. (2001). El rancho mar: pesca, familia y cultura en un pueblo de la costa de Michoacán. México: El Colegio de Michoacán.

Luque, D. \& Robles, A. (2006). Naturalezas, saberes y territorios 
comcaác. México: SEMARNAT, INE, CIAD.

Marín G., G. (2000). Holbox. Antropología de la pesca en una isla del Caribe mexicano. México: El Colegio de Michoacán, Centro de Investigación Científica de Yucatán.

Mendoza Pérez, L. A. (2011). "El ferrocarril y las poblaciones de Campos, Manzanillo y Armería a principios del siglo XX". La Palapa, Vol. VI, № 12.

Ochoa, A. (1988). Antropología de la gente de mar. Los pescadores de sardina en Ensenada, Baja California. México: INAH.
Ramírez, L. (1989). Caciquismo y miseria rural. (Tesis de Licenciatura en Antropología Social). UAM-Iztapalapa.

Santana, R. (2013). Entrevista realizada por Francisco Javier Verduzco Miramón el 28 de febrero. Colonia Alameda, Manzanillo.

SEMARNAT (2013). Estadísticas del agua. México: Secretaría de Medio Ambiente y Recursos Naturales.

Vargas, A. (2015). Entrevista realizada por Aura Helena Ramírez Corona el 14 de mayo. El Rebalsito de Apazulco, Jalisco, México. 


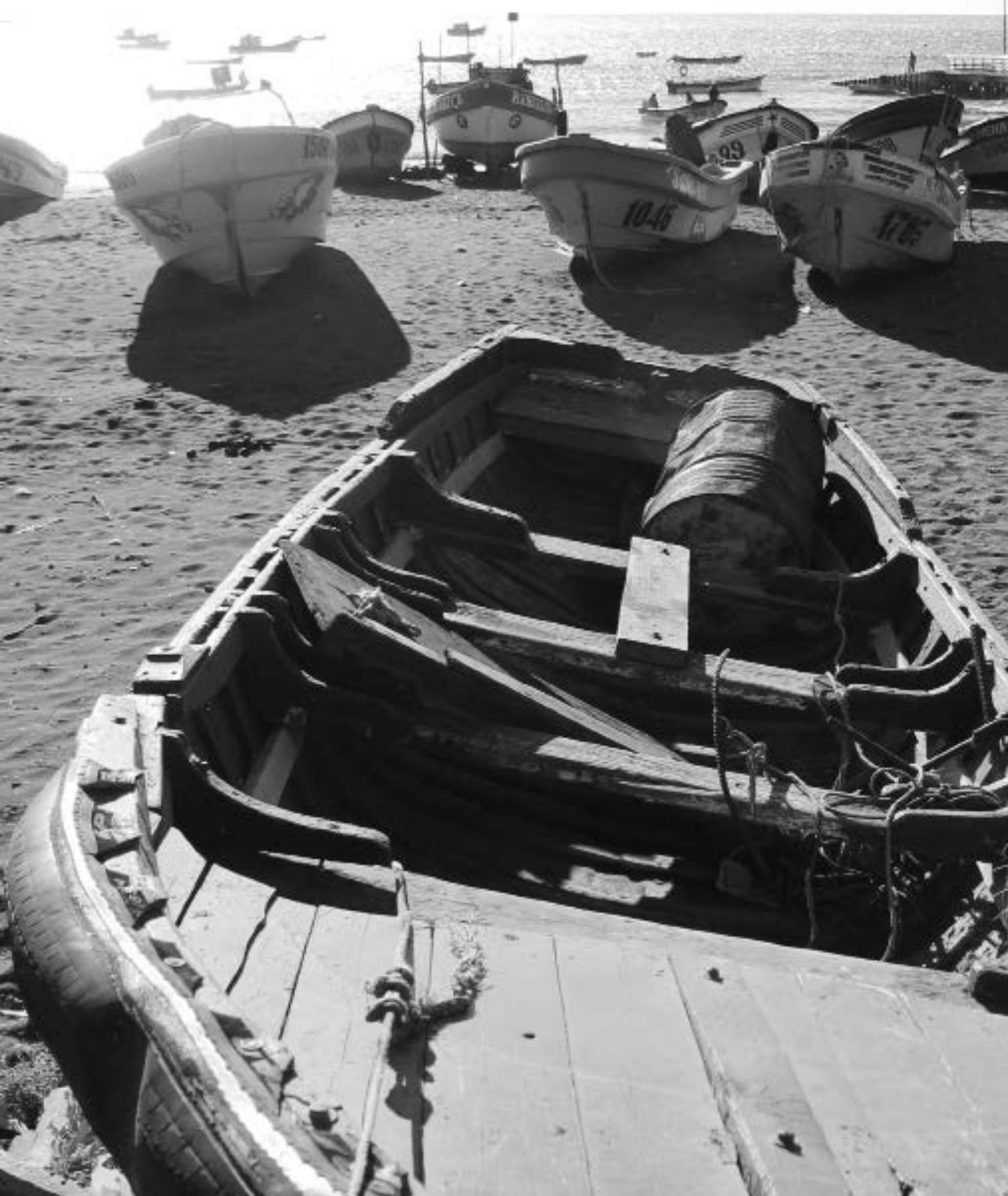

